\title{
Carnets
}

Revue électronique d'études françaises de l'APEF

Deuxième série - 19 | 2020

Petite fabrique d'interprètes

\section{Viagens à Pérsia nos anos 30 : Maud Von Rosen e Robert Byron}

\section{Gonçalo Vilas-Boas}

\section{(2) OpenEdition}

1 Journals

\section{Édition électronique}

URL : http://journals.openedition.org/carnets/11284

DOI : 10.4000/carnets. 11284

ISSN : 1646-7698

Éditeur

APEF

Référence électronique

Gonçalo Vilas-Boas, «Viagens à Pérsia nos anos 30 : Maud Von Rosen e Robert Byron », Carnets [En ligne], Deuxième série - 19 | 2020, mis en ligne le 31 mai 2020, consulté le 23 décembre 2020. URL : http://journals.openedition.org/carnets/11284; DOI : https://doi.org/10.4000/carnets.11284

Ce document a été généré automatiquement le 23 décembre 2020.

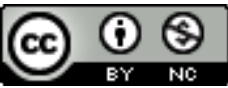

Carnets est mis à disposition selon les termes de la licence Creative Commons - Atribution - Pas d'utilisation commerciale 4.0 International. 


\title{
Viagens à Pérsia nos anos 30 : Maud Von Rosen e Robert Byron
}

\author{
Gonçalo Vilas-Boas
}

\section{NOTE DE L'AUTEUR}

Este artigo foi desenvolvido no âmbito da investigação financiada por Fundos Nacionais através da FCT - Fundação para a Ciência e a Tecnologia -, enquadrado no Programa Estratégico "UIDP/ELT/00500/2020". Agradeço o trabalho de tradução de grande parte do texto a Cristina Vilas-Boas.

1 Dedico este espaço aos livros Insh'Allah (1935) da sueca Maud von Rosen e The road to Oxiana (1937) do inglês Robert Byron pela então ainda denominada Pérsia. ${ }^{1}$ Essa zona foi visitada, entre muitos outros, por Ella Maillart e Annemarie Schwarzenbach e, mais tarde, por Nicolas Bouvier, com o seu L'usage du monde (1963), autor a quem Maria Hermínia Laurel dedicou vários ensaios. E se von Rosen é bastante desconhecida ${ }^{2}$, o mesmo não se pode dizer de Byron, autor lido por quase todos os viajantes àquela zona e traduzido em muitas línguas, incluindo o português.

2 Temos que distinguir os viajantes em si, com os seus próprios contextos e a viagem que de facto efectuaram, e os sujeitos textuais, que diferem dos autores reais, por serem sempre ficcionalizações, ainda que construídas a partir das memórias das viagens efectuadas. Ao escreverem seleccionam só partes do que vivenciaram, do que se recordam e a memória pode enganar-nos. Desse modo, os textos representam somente fragmentos das memórias das viagens, transpostas para viagens textuais. Também é preciso ter em conta o tempo decorrido da viagem e o período da escrita : quanto maior a distância temporal, maior espaço haverá para a construção estética, não sendo a 'verdade' um valor essencial, mas tendo obviamente em conta a necessidade da verdade factual. Há, contudo, uma espécie de pacto, o "pacto referencial " como lhe chama François Hourmant (apud Cogez, $2004: 22$ ). O leitor tem que acreditar que os factos relatados são verídicos, identificáveis, enquanto a ordem e os aspectos subjetivos, as 
reacções pessoais são aceites como tais. O todo passa a ser visto como uma adaptação subjetiva aos intuitos e estratégias estéticas no processo da escrita. Não são guias de viagem ou relatos geográficos rigorosos, mas reacções individuais face a esses espaços.

Viajar significa encontrar o/a Outro/a no seu próprio contexto, mas a partir de um ponto de vista exterior, o do viajante. Em qualquer deslocação levamos sempre connosco as nossas raízes, levamos parte dos nossos contextos sociais, culturais, históricos, que condicionam a nossa maneira de ver. O viajante leva consigo informações prévias, textos de outros viajantes. Não vivendo na zona, como foram o caso da britânica Gertrude Bell ou da suíça Isabelle Eberhardt, que viveram largos anos em sociedades islâmicas, é sempre um olhar fugaz, fugidio, necessariamente fragmentário e com informação 'prévia'.

o Médio Oriente é, desde há muito, uma importante parte da identidade europeia, cuja história e religião apresentam fortes ligações àquela região do mundo. Os europeus construíram uma representação destes povos, não sendo fascinados por eles, mas pelas imagens que deles tinham, projeções de desejos e receios imaginados. Já era assim desde o Renascimento, aguçando-se ainda mais a curiosidade durante o Romantismo. Foi nesta época que o Oriente passou a ser visto na Europa, entre muitos outros atributos, como a origem de um hedonismo discursivo, do exotismo, do erotismo, da imagem dos califados e dos seus costumes. Projetavam nele o que a cultura local proibia, refletido na construção cultural do Outro. Eram assim objectos de desejo. Mas também era comum, mormente no discurso popular, uma demonização do oriental, representando o mal face ao bom ocidental. As interpretações europeias - por vezes, mais adaptações do que traduções - de Mil e Uma Noites ${ }^{3}$ foram importantes fontes de inspiração, tal como o foram alguns poetas árabes e persas. Recordemos Cartas Persas ${ }^{4}$ (1721), de Montesquieu, ou West-östlicher Divan ${ }^{5}$ (1819), de Goethe, nenhum dos dois tendo visitado a região. A vasta literatura de viagens dos séculos XIX e XX corrigiu algumas destas imagens, mas o fascínio perdura: os "velhos" poetas continuam a atrair uma enorme variedade de leitores, independentemente das diferentes realidades políticas naqueles países. Como podemos verificar nos textos aqui presentes, há um grande interesse pela componente arqueológica e arquitetónica. Também o nomadismo atraiu muitos europeus mais curiosos, perdurando ainda a importância das tradicionais imagens de palácios, da sensualidade e da crueldade ${ }^{6}$.

5 Irei apenas tecer algumas considerações a partir da visão " orientalista » que uma sueca e um britânico têm da Pérsia, cujo líder, o autocrata xá Pahlevi, estava fortemente interessado numa certa ocidentalização, enquanto era simultaneamente cobiçado pelos ingleses, pelos franceses e pelos americanos por causa do petróleo. Nesta fase, a visão imperialista e colonialista era de grande complexidade, uma vez que os poderes estratégicos e os jogos de poder se encontravam em rápidas mudanças. Deste modo, ainda que as imagens estereotipadas mais tradicionais tenham persistido, dificilmente suportaram um confronto com as imagens trazidas pelos novos viajantes, que questionavam, de uma forma ou de outra, as representações anteriores, complementando-as ou corrigindo-as. No entanto, um traço em comum que une os viajantes nos anos 30 : a consideração de que os ocidentais são superiores, o próprio facto de se poderem deslocarem facilmente demonstra a sua superioridade civilizacional. Três temas, entre outros, podem ser frequentemente detetados nos relatos de viagem neste tempo: a posição das mulheres, a burocracia e as infraestruturas de transportes. 
Começo pelo livro mais antigo, o da Condessa sueca Ella Clara Lillian Maud von Rosen (1902-1988). Pouco se sabe sobre a autora, para além do seu interesse por cavalos. Foi casada com um conde diplomata, seu primo, e aquando do seu terceiro casamento, tornou-se também escultora e escreveu uma biografia sobre o seu pai, Hjärtats kavaljer. Clarence von Rosen (1979) sob o nome de Maud Engberg. Enquanto o primeiro marido estava colocado em Washington como adido militar, ela viajou pelos Estados Unidos e escreveu a obra Vi titta på Amerika [Olhamos para a América] (1933). Dois anos mais tarde, viajaria sozinha para a Pérsia, onde foi jornalista durante alguns meses. Insh'Allah! (Om Gud Vill) foi inicialmente publicado na revista Idun e mais tarde em formato de livro. Nos anos 30 , algumas editoras estavam interessadas em publicar livros de viagens, pois vendiam-se bem e representavam uma forma de dar aos leitores uma escapatória da sua vivência em plena crise europeia. Lucrativos, levavam as editoras a pagar antecipadamente, o que permitia aos autores viajarem. Maud von Rosen quis publicar Insh'Allah! como um livro, sendo essa uma das razões que a levaram a não usar diretamente o formato de um diário, como fizeram muitos escritores de viagens. Analisemos rapidamente o subtítulo: "A história de uma viagem pela Pérsia, com as suas experiências e aventuras » (Upplevelser och äventyr under en resa i Persien). A autora centra a sua atenção no sujeito da viagem, não tendo qualquer propósito específico para a jornada em que embarca. Não é tanto o objeto da viagem que importa, mas sim a reação subjetiva e a curiosidade perante esse país. Alguns críticos aventam a hipótese do pouco sucesso do livro pelo facto de o pai e o tio terem sido simpatizantes do nazismo algo normalmente visto mal na Suécia da época.

7 Maud von Rosen dedica o livro a engenheiros suecos e escandinavos que ali conhece e que lá estavam "para apoiar a nação iraniana no seu objetivo de a desenvolver e de melhorar, sob a liderança de um regente poderoso, um país já de si encantador » (MR$\mathrm{E}: \mathrm{v} ; \mathrm{MR}-\mathrm{S}: \mathrm{7}^{7}$. $\mathrm{O}$ título sugere o seu entusiasmo pelo país e o seu desejo de não o apresentar de acordo com a perspetiva europeia dominante. Numa manhã, no salão de cabeleireiro, lembrou-se da conversa com uma estrangeira « com umas gotas de sangue sueco » (MR-E : $23 ;$ MR-S : 22) ${ }^{8}$, que diz à narradora : «Não sabe com tem sorte em poder viajar pelo Oriente, Visitar um país com hábitos tão diferentes, que mostra uma outra face e uma mentalidade tão distante da nossa que se torna um problema percebêla. Deve ser uma experiência a não perder » (MR-E : 23 ; MR-S : 22). Esta citação é do início do segundo capítulo, demonstrando desde logo ao leitor as dificuldades e os desafios com que Maud von Rosen se deparou. De forma a compreender o país, a autora não dá apenas voz ao seu ponto de vista, mas às perspetivas preconceituosas de outros estrangeiros e sobretudo a de alguns persas - como o príncipe Mosteazan, ou um diretor de um banco -, para que a sua perspetiva europeia "orientalista " possa ser corrigida ou legitimada por persas. « 'O que pensa do nosso país?', perguntou uma das senhoras com uma voz amistosa » (MR-E : 15 ; MR-S : 14). Como aristocrata é óbvio que tem muitos contactos com as autoridades e pessoas influentes, participa em caçadas, recebe mesmo um cavalo como prenda. Mas não se limita a estes. Desde o início surge a evidência de que Maud von Rosen tem um problema para resolver: por um lado, aprecia os esforços de Reza Shah Pahlevi para modernizar o país, principalmente através da renovação das miseráveis redes de transportes existentes em muitas partes do território. Por outro lado, a autora receia justamente que as tradições, o modo de vida na Pérsia, os nómadas e os seus camelos, a cultura, pudesse vir a ser destruída pela máquina civilizacional do ocidente. $\mathrm{O}$ dilema é revelado de forma clara por meio da tensão entre o texto e as 91 fotografias, tiradas pela própria autora ${ }^{9}$. Num artigo muito 
interessante, Maria Cronqvist e Agneta Edman analisam a relação entre os textos de von Rosen e as fotografias incluídas no original sueco : a autora descreve por palavras (as suas e as de outras personagens citadas) a modernização da Pérsia, mas as suas fotografias, pelo contrário, retratam apenas o tradicional, os aspetos etnográficos; nenhuma fotografia mostra os trabalhos de que o Xá mais se orgulhava, à exceção da fotografia de uma ponte construída pelos suecos (Cronqvist, Edman, 2001 : 254-262). São imagens fora do contexto textual (id. : 246), o que significa que não representam uma continuidade ou uma ilustração daquilo que o texto contém. Esta dualidade de « linguagens » de Maud von Rosen expressa coisas diferentes e demonstra a própria dicotomia da autora no que diz respeito às diferentes forças em confronto.

Tal como a maioria dos viajantes, também von Rosen estabeleceu contactos com outros estrangeiros na Pérsia ${ }^{10}$. O primeiro ocorreu num salão de cabeleireiro em Teerão. É aqui que a autora conhece algumas senhoras persas, cujo sonho era visitar a Europa, sobretudo para ir às compras, nomeadamente meias de seda! Numa outra ocasião, fala com algumas estrangeiras, com destaque para uma senhora inglesa, que demonstraria "uma ignorância soberana ». Em seguida, von Rosen fala com outra britânica, que estava a « explorar o Oriente» (MR-E : 222 ; MR-S : 274), mas que se sentia desiludida por não encontrar o lado romântico da viagem, aquele transmitido pelo discurso orientalista e colonialista. Isto demonstra que este tipo de discurso ainda subsistia e que fazia parte da identidade de alguns estratos sociais - os que tinham dinheiro para viajar : « Não encontrei qualquer esplendor oriental em parte alguma do Oriente » (MRE : 223; MR-S : 275) ${ }^{11}$. É pela voz desta senhora inglesa que von Rosen consegue apresentar algumas formas europeias de apreciar o país, muito diferentes das suas. Estas britânicas procuram o oposto à vida britânica, mas sob a perspectiva da superioridade da sua própria civilização, uma utopia fabricada no Ocidente, e com tal sem correspondência na realidade.

9 Não irei salientar aqui os temas que von Rosen retrata sobre a Pérsia e que são comuns aos da maioria dos viajantes : os bazares, o trânsito horrível devido às más estradas, alguma insegurança, os fumadores de ópio, os véus utilizados obrigatoriamente pelas mulheres e os curiosos chapéus de Pahlevi, que o Xá obrigava os homens a usar. Importa referir que a autora não quis escrever sobre Persépolis - ou viajar até lá sequer - porque já muitos haviam escrito sobre as suas ruínas, e sobre as quais nada mais havia a dizer. Maud von Rosen interessa-se por inúmeros aspetos da vida na Pérsia, incluindo a dança local, cuja delicadeza é paralela à da poesia persa, ou à da decoração (MR-E : 109-110 e 58 ; MR-S : 124-5 e 63) e tem o cuidado de utilizar o discurso direto, em que as diferentes pessoas apresentam os pontos de vista locais. Deste modo, o leitor consegue uma visão ampla do país, sob a perspetiva das classes média e alta, mas sempre numa perspectiva multicultural. A autora ficou muito impressionada pela forma como os persas respondem tantas vezes a todo o tipo de questões por meio de provérbios, bem como pela sua atitude em relação ao tempo, num país em que a pressa não existe. Para compreender o Irão, há que compreender o Islão : é por isso que von Rosen dedica três capítulos às conversas que teve com um mullah, conseguindo assim distanciar-se do discurso estereotipada sobre o Islão, nomeadamente para perceber, entre outras coisas, o ponto de vista religioso sobre o tratamento das mulheres.

10 Uma forma de demonstrar o contraste entre civilizações é comparar situações. A autora fá-lo ao demonstrar a perplexidade das mulheres iranianas perante a forma como as mulheres são tratadas na Europa, como se pode verificar no seguinte exemplo : «Elas 
espantaram-se quando um dos diretores me ajudou educadamente a montar a melhor mula. Ali, era irrelevante o animal em que a mulher ia, desde que os homens viajassem segura e confortavelmente. » (MR-E : 204 ; MR-S : 251).

11 Admiravam ainda o facto de verem uma mulher poder viajar sozinha, sem o marido. Um iraniano até a quis comprar por 15 tomans (à época, o equivalente a cerca de $€ 2$ ) ${ }^{12}$, roupa incluída! As raparigas persas não podiam escolher os seus maridos - isso era assunto para as famílias discutirem. Este tipo de atitude relativamente às mulheres não era exclusivo do Irão - era assim também noutros países muçulmanos.

12 O livro termina com uma situação ambígua, que demonstra o dilema vivenciado por von Rosen no decurso da viagem : desta feita, uma procissão em honra de Hussein, tradição islâmica xiita. A autora acaba por descobrir mais tarde que esta procissão a que assistiu não fora a verdadeira, mas uma falsa, organizada propositadamente para que ela pudesse descrevê-la. Ainda assim, as últimas linhas do livro denotam um tom muito positivo: "Sim, Mullah Mohammed Ali, voltarei com prazer ao Irão, Insh'Allah. »(MR-E : 288 ; MR-S : 363).

Robert Byron (1905-1941) era um escritor de viagens britânico, bem conhecido pela obra A Estrada para Oxiana ${ }^{13}$, mas não por outras obras que escreveu, que alguns classificam de aborrecidas. De uma família de classe alta, Byron tomou posição contra o fascismo e contra qualquer atitude anti-humanista, fosse ela política ou religiosa. Ao contrário de Maud von Rosen, Byron tinha um propósito particular para as suas viagens : queria sobretudo estudar a arquitetura local islâmica, e neste caso específico do Império Seljúcida (1057-1194), da Dinastia Timúrida (1387-1502) e da Dinastia Safávida (1502-1737) ${ }^{14}$. Bruce Chatwin, outro paradigmático escritor de viagens britânico, escreveu, na introdução da edição Picador do livro, datada de 1981, que Byron elevou o livro « ao estatuto » de " livro sagrado », e que por isso estava « além de toda a crítica » (RB : 9). Há até quem veja Byron como um esteta entre os escritores de viagens. É o caso, por exemplo, do autor William Dalrymple ${ }^{15}$.

14 A viagem é preparada pela leitura de Ten Thousand Miles Across Persia, de Percy Sikes, ou Survey of Persian Art, de Arthur Upham Pope, entre outras obras. Falava-se das suas possíveis ligações aos Serviços Secretos britânicos, tal como T.E. Lawrence, o famoso Lourenço da Arábia (ver Ramade, 2001: 65-66). Byron era extremamente crítico em relação a outros viajantes :

Conhecemos bem estes viajantes modernos, estes delegados de turma que cresceram depressa demais e os pseudocientistas enfadonhos para aqui enviados por congregações de funcionários apagados para verificar se as dunas de areia cantam e se a neve é fria. Têm o apoio de fundos ilimitados e de todo o tipo de influência oficial. Chegam aos recantos mais longínquos da Terra, mas para além de comprovarem que as dunas cantam realmente e que a neve é mesmo fria, que observam eles que enriqueça o espírito humano ? Nada. (RB : 343$)^{16}$

Byron viajou durante dez meses com o amigo Christopher Sykes, um diplomata britânico, também ele muito interessado em arquitetura. Por vezes, Sykes é mencionado na narrativa, noutras torna-se mesmo uma personagem; mas como normalmente acontece neste tipo de texto, o acompanhante de viagem tem um papel muito secundário e pouco se sabe sobre ele no decorrer da deslocação ${ }^{17}$. Byron escreveu o livro depois da viagem (na Inglaterra e, mais tarde, na China), « mas manteve o estilo típico de um diário e a impressão de que escrevia a grande ritmo durante a viagem » (Booth, $2002: 166$ ). 
16 Este livro, assumindo o formato de diário, inicia-se em Veneza a 20 de agosto de 1933, com as entradas correspondentes relativamente ao tempo e ao lugar. Os dois embarcam num navio em direção ao Chipre e à Palestina, seguindo-se a Síria e o Iraque até chegarem à Pérsia. Esta parte tem cerca de 30 páginas $^{18}$. A estadia na Pérsia é relatada ao longo de cerca de 126 páginas, ao passo que a passagem pelo Afeganistão é descrita ao longo de cerca de 90. O regresso, via Índia, e a viagem marítima, são contados em apenas quatro páginas. Na Pérsia, atravessam primeiro o Norte, seguindo depois para o Afeganistão - sobretudo para visitar a bela cidade de Herat, a que Byron dedica 23 páginas. Regressam depois à Pérsia, desta feita para viajarem pelo Sul, que Byron aprecia muito mais devido à sua riqueza arquitetónica. Esta distribuição demonstra o interesse revelado face às diferentes regiões.

O escritor critica fortemente a abordagem «orientalista » de muitos viajantes desta parte do mundo, sobretudo dos britânicos, que conhece aqui e ali, em festas ou ao passar por algumas cidades ${ }^{19}$. «Contudo, nesta obra de Byron, tudo é levado a extremos engenhosos, utilizados de forma certeira para deflacionar o discurso ocidental do Orientalismo » (Pfister, 1999 : 484). Byron é também muito crítico do Xá, « [p]arece que nos aproximamos de uma tirania medieval com susceptibilidades modernas » (RB : 62 ; 44). O xá é sempre ironicamente apelidado de Marjoribanks : «Chiu. Não deves falar do xá em voz alta. Chama-lhe Sr. Smith. (...) É melhor chamar-lhe Marjoribanks para nos lembrarmos de quem estamos a falar» (RB : 62). Byron compreende a necessidade de modernização, mas não consegue aprovar os meios tirânicos para lá chegar. Um exemplo são os chapéus que todos os homens são forçados a usar : «Porque é que o xá os obriga a usar aqueles chapéus?» (RB:62).

Poderemos dizer que este diário lida sobretudo com dois assuntos : por um lado, as condições da viagem (os difíceis acessos, especialmente quando chove, devido às cheias fluviais repentinas ou às estradas bloqueadas por pedras caídas); e, por outro, as descrições arquitetónicas, ligadas à história dos edifícios descritos. Essa narração da viagem é de leitura fácil, por ser tão viva e bem escrita, independentemente de viajarem de táxi, em carro de aluguer ou em carro próprio (um Austin, muito antigo, comprado no local, que, aliás, teve que abandonar passados alguns quilómetros), em camiões, autocarros ou cavalos. Todos os meios de transporte públicos lhes permitiam conhecer diversas pessoas, bem como membros da autoridade, com as suas práticas burocráticas altamente complicadas. Não raras vezes, Byron cita diálogos, que são frequentemente partes muito divertidas do texto. De forma a ser o mais realista possível, o autor refere as marcas dos carros e dos camiões : Reo, Chevrolet, Austin, Bedford e Rolls-Royce, pertencentes aos seus amigos, que vai conhecendo ao longo da jornada (o que ajuda à sua definição social!). Uma situação irónica é a dos Rolls a carvão ${ }^{20}$, tecnologia que os britânicos estavam a desenvolver e que nesta viagem provou ser um fracasso! A descrição dos edifícios, sobretudo de mesquitas, palácios e monumentos é maravilhosa, ainda que por vezes muito extensa.

A Estrada para Oxiana é « um livro surpreendentemente político », como afirma Pfister :

Este novo ênfase nos contextos políticos globais ou locais alternam entre o livro de viagens moderno e o jornalismo ou a reportagem. E esta alternância genérica tem consequências bastante vastas para a representação do Outro: as fantasias intemporais do Oriente e do Oriental dão lugar a uma consciência de concretas e manifestas relações de poder historicamente determinadas ou são, pelo menos, de certa forma compensadas por essa consciência. (Pfister, 1999 : 472/3). 


\section{Byron, ainda que os factos sobre a Pérsia e sobre o Afeganistão sejam apenas mencionados de passagem.}

Byron percebe que os persas não são propriamente adeptos dos britânicos : o Xá chegou ao poder com ajuda da Grã-Bretanha, mas rapidamente começaria a pensar por si próprio; os problemas não tardariam, sobretudo por causa dos interesses coloniais ligados ao petróleo ${ }^{21}$. $\mathrm{O}$ objetivo de Byron era o de questionar o predomínio e o uso unívoco de narrativas colonialistas e ocidentais. (...) Byron não consegue totalmente ultrapassar os preconceitos e os desequilíbrios do seu tempo " (Booth, $2002: 163 / 417$ ). Também os iranianos não estavam particularmente satisfeitos com o facto de os arqueólogos britânicos, alemães e americanos ali fazerem escavações e levarem tantos artefactos persas de valor para os seus respetivos países (RB : 164).

Algumas páginas são dedicadas à paisagem e aos impressionantes jardins dos persas mais ricos e poderosos (por exemplo, RB: 145). Byron ficou particularmente entusiasmado com as estepes de Gonbad-e-Qabus :

Ao deixar o planalto, sentimo-nos animados. Mas agora o nosso ânimo efervescia. Dávamos gritos de alegria e parámos o carro para que não passassem tão depressa os minutos que nos privavam daquela primeira visão irrepetível. Naquele paraíso, até as cotovias haviam perdido o seu habitual recato. Uma quase chocou com o meu chapéu, querendo satisfazer a sua curiosidade (RB : 286)

Mais tarde, Byron refere-se à sua própria descrição nos seguintes termos :

[Os superlativos aplicados por viajantes a objectos por eles vistos, mas desconhecidos da maioria das pessoas, são geralmente suspeitos. Eu sei disso, pois sou culpado de os usar. Mas ao reler este diário dois anos mais tarde, num ambiente mais contrastante (Pequim), mantenho a opinião que tinha antes de ir à Pérsia, e que confirmei aquela tarde na estepe : Gonbad-e-Qabus está entre os edifícios mais grandiosos do mundo.] (RB : 288)

24 A ironia está sempre presente, principalmente quando o autor observa, à distância, os seus contactos com os persas ou demais estrangeiros ; é irónico até mesmo com a arte, quando desgosta dela. Um bom exemplo disto é a sua descrição de gravuras nas rochas em Naksh-i-Rustam :

Um grupo sassânida ${ }^{22}$. O rei - de calças à cowboy em musselina, sapatos de ponta quadrada, longas fitas ondulantes e chapéu abalonado - está virado para uma figura alegórica com uma coroa municipal, coberta de cachos de cabelo, que poderia ter sido desenhada pelo cartoonista Bernard Partridge ${ }^{23}$. (RB : 228)

Quando Byron não está particularmente interessado num determinado tema, passa apenas fugazmente por ele, deixando talvez apenas um comentário irónico, que carateriza mais o autor do que o objeto. Não lhe apraz, por exemplo, a literatura persa antiga, mesmo sendo contemporânea dos edifícios que ele tão avidamente descreve. Sobre Ferdusi (935-1020) ${ }^{24}$, autor da obra épica nacional persa, Shahnama, Byron escreve o seguinte :

[N]o ano que vem, celebra-se o milésimo aniversário do nascimento de Ferdusi. os estrangeiros já ouviram dele. Apreciam-no na medida em que é possível apreciar um poeta que nunca ninguém leu. E, por isso mesmo, espera-se que as homenagens sejam prestadas não tanto à obra, mas à nacionalidade de Ferdusi. Essa é, pelo menos, a esperança dos persas. (RB : 113) 

de estar. A forma como os dois autores viram a Pérsia dependia não apenas deles, ou da sua formação estratégica, mas também dos discursos existentes sobre a Pérsia, quer os predominantes, quer aqueles que os dois haviam lido antes de iniciarem as suas viagens. Através das respetivas linguagens, eles também estão a transmitir outros discursos que não os deles. A linguagem é um instrumento para compreender a vida, o mundo, a política e o poder ! o leitor é submetido a um discurso dual : o do viajante e o do outro - este transposto da sua respetiva "linguagem». Viajar significa ter a possibilidade de alterar ou de negar os imagótipos, os clichés; representa abrir o discurso a outras dimensões. E, apesar de serem relatos dos anos 30, ainda são atuais 
com as informações e perspetivas apresentadas. São úteis para se perceber o Outro, mas também para se perceber os Europeus.

\section{BIBLIOGRAPHIE}

\section{Textos}

BYRON, Richard (1981). The road to Oxiana. London: Picador/Pan.

BYRON, Richard (2014). A Estrada para Oxiana, trad. Raquel Mouta. Lisboa : Tinta-da-China.

ROSEN, Maud von (1935). Insh'Allah (om Gud vill). Upplevelser och äventyr under en resa i Persien. Stockholm: Lars Hökerbergs Bokförlag.

ROSEN, Maud von (1937). Persian Pilgrimage. Being the story of a journey through Persia with its experiences and adventures, trad. Evelyn C. Ramsden. London: Robert Hale.

\section{Bibliografia crítica}

BERG, Magnus (2005). «Den portionsförpackade Orienten », in Moa Matthis, Orientalism på Svenska. Stockholm: Ordfront, pp. 56-86.

воотн, Howard J. (2002). « Making the Case for Cross-Cultural Exchange: Robert Byron's The Road to Oxiana ", in Charles Burdett and Derek Duncan (ed.). Cultural Encounters. European Travel writing in the 1930s. New York/Oxford: Berghahn Books, pp. 159-172.

BURDETT, Charles and DUNCAN, Derek (ed.) (2002). Cultural Encounters. European Travel writing in the 1930s. New York/Oxford: Berghahn Books.

BURUMA, Ian e MARGALIT, Avishai (2005). Ocidentalismo. Uma beve história da Aversão ao Ocidente, [Occidentalism. A short story of Anti-westernism, 2004]. Mem Martins: Europa-América.

CATOMERIS, Christian (2005). « Svartmuskiga bandittyper - svenskarna och det mörka håret », in Moa Matthis (2005). Orientalism på Svenska. Stockholm : Ordfront, pp. 20-55.

COGEZ, Gérard (2004). Les écrivains voyageurs au XXe Siècle. Paris : Seuil.

CRONIN, Michael (1995). « Andere Stimmen ; Reiseliteratur und das Problem der Sprachbarrieren ", in Anne Fuchs/Theo Harden (eds.). Reise im Diskurs. Modelle der literarischen Fremderfahrung von den Pilgerberichten bis zur Postmoderne. Tagungsakten des Internationalen Symposiums zur Reiseliteratur, University College Dublin vom 10.-12. März 1994. Heidelberg: C. Winter, pp. 19-34.

CRONQVIST, Marie and EDMAN, Agneta (2001). « Resa i centrum. Bild, text, modernitet och tradition i två reseskildringar av Maud von Rosen », in Lars M. Andersson, Lars Berggren \& Ulf Zander (red.). Mer än tusen ord. Bilden och den historiska vetenskaperna. Lund: Nordic Academic Press, pp. 245-266. FLEISCHMANN, Uta (ed.) (1993). Wir werden es schon zuwege bringen, das Leben. Annemarie Schwarzenbach an Erika und Klaus Mann. Briefe 1930-1942. Pfaffenweiler : Centaurus. 
FORSDICK, Charles (2002). « Sa(l)vaging Exoticism: New Approaches to 1930s Travel Literature in French ", in Charles Burdett and Derek Duncan (ed.). Cultural Encounters. European Travel writing in the 1930s. New York/Oxford: Berghahn Books, pp. 29-45.

GRONKE, Monika (2003). Geschichte Irans. Von der Islamisierung bis zur Gegenwart. München : Beck. KNOX, James (2004). A biography of Robert Byron. London: John Murray.

MACKENZIE, John M. (1996). Orientalism. History, theory and the arts. Manchester/New York: Manchester University Press.

MAILlART, Ella (2000). Via Cruel. Porto : Civilização.

MOURA, Jean-Marc (1998). L'Europe littéraire et l'ailleurs. Paris : PUF.

PFISTER, Manfred (1999). « Robert Byron and the modernisation of travel writing », Poetica. Zeitschrift für Sprach- und Literaturwissenschaft. München, 31. Band, 1999, Heft 3-4, pp. 462-487. RAMADE, Fréderic (2001). Literarische Reise durch Persien. Auf den Spuren von Pierre Loti, Robert Byron and Annemarie Schwarzenbach. [La Perse des Écrivains Voyageurs, 1999]. München: Knesebeck. SAID, Edward (1995). Orientalism. Western Conceptions of the Orient. London: Penguin.

SCHWARZENBACH, Annemarie (1989). Bei diesem Regen, in Roger Perret (ed.), Basileia: Lenos. THACKER, Andrew (2002). « Journey with Maps: Travel Theory, Geography and the Syntax of Space ", in Charles Burdett and Derek Duncan (ed.). Cultural Encounters. European Travel writing in the 1930s. New York/Oxford: Berghahn Books, pp. 11-28.

URE, John (2004). In search of Nomads. An English obsession from Hester Stanhope to Bruce Chatwin. Londres: Robinson.

YoUNGS, Tim (2004). « The Importance of Travel Writing », The European English Messenger, vol. 13.2, Autumn 2004, pp. 55-62.

\section{NOTES}

1. A Pérsia passou a designar-se oficialmente Irão a partir de 1935. "O nome Irão do persa moderno deriva do termo proto-iraniano Aryānā, que significa "terra dos arianos", palavra registada pela primeira vez no Avesta da tradição do zoroastrismo. $O$ termo Ērān foi encontrado em referência ao Irão, numa inscrição persa do século III e numa inscrição parta onde o termo aryān é usado em referência aos iranianos » (vd. Wikipedia : « Irão », visto a 15.03.2020).

2. Para além da tradução inglesa de 1937, só existe, de que eu tenha conhecimento, uma tradução em farsi (persa) bastante recente, numa pequena edição. Também não há novas edições em livro na Suécia.

3. A primeira tradução europeia surgiu em França entre 1704 e 1717. Poderemos considerar que se trata mais de uma adaptação do que uma tradução fidedigna, mas foi esta a que originou a receção europeia da obra.

4. Nota de tradutor: Lettres Persanes, no original.

5. Nota de tradutor : em português, O Divã Ocidental- Oriental.

6. Ver, por exemplo, Ure (2004).

7. A Suécia estava a cooperar com a Pérsia, quer na construção de infraestruturas rodoviárias e ferrovias, quer na preparação das forças policiais. Per Nyström escreveu um livro sobre os cinco anos que ali passou como militar: Fem år $i$ Persien som gendarmofficer (1910). A imprensa sueca elogiou a atuação dos polícias suecos, demonstrando uma vez mais a superioridade deste povo 
europeu quando comparado com o povo persa. Mas outros viam nesta presença um apoio à ditadura, assinalando até que os polícias haviam matado muitos «bandidos » - termo utilizado pelo regime para se referir aos seus opositores (cf. Catoremis, $2005: 24$ ).

8. A tradução inglesa Persian Pilgrimage. Being the story of a journeu yhrough Persia with its experiences andadventures é referida como MR-E, o original sueco como MR-S, seguido da indicação da página. 9. A tradução inglesa apenas publica 32 das fotografias e separadas do texto, mostrando muitas vezes precisamente o oposto. A fotografia do Xá não é publicada na tradução. Segundo Marie Cronqvist e Agneta Edman, ainda que a autora não quisesse a fotografia do regente impressa, a editora decidiu publicá-la, de modo a corresponder às práticas editoriais da época, respeitantes a livros sobre a Pérsia. (Cronqvist, Edman, 2001: 255). Na edição inglesa a fotografia do xá é substituída por uma da autora a cavalo na Pérsia.

10. Uma das estrangeiras que a autora conheceu foi Annemarie Schwarzenbach, que não é mencionada no livro. Schwarzenbach escreveu o conto « Eine Frau allein », em que a personagem principal é baseada em Maud von Rosen. Nesta história, von Rosen é uma extravagante baronesa da Dinamarca, Katrin Hartmann de seu nome (a mãe de von Rosen era, de facto, dinamarquesa), que viajava sozinha com o propósito de escrever um livro sobre a Pérsia. Mas os acontecimentos deste conto não coincidem com os relatos de von Rosen. Schwarzenbach admirava-a, mas teve de a camuflar na história. Há, ainda assim, alguns paralelismos em relação às viagens de von Rosen : o momento em que conhece o príncipe Mosteazan, aqui denominado Karagöl ; o alojamento no hotel Naderi, em Teerão; a admiração pelo poeta Ferdusi ; o amor por cavalos ; o facto de a personagem, tal como von Rosen, ter decidido não ir a Persépolis, sobre a qual já tantos haviam escrito. Uma fotografia está publicada no livro de Annemarie Schwarzenbach (1989: 235). Existem outras fotografias tiradas por Annemarie Schwarzenbach, durante o seu encontro na Pérsia. Estão actualmente no Arquivo Literário Suíço, em Berna, mas estão igualmente disponíveis online. Numa carta dirigida a Klaus Mann, Schwarzenbach escreve : «(...) noites bem longas com a Condessa Rosen, que é alguém entre Maria e Greta Garbo, linda como um arcanjo, levando a uma confusão das mentes - pelo menos a mim. » (Schwarzenbach, apud Fleischmann, $1993: 120)$.

11. A senhora inglesa, de facto, representa como o Ocidente via o Médio Oriente, baseada em estereótipos - como os aspetos místicos, exóticos, eróticos, mostrando os homens orgulhosos das montanhas e dos desertos. Destacava apenas o modo de vida pré-moderno, já inexistente nas civilizações ocidentais. Era uma perspetiva utópica, um discurso baseado em estereótipos : a brutalidade dos patriarcas, portanto um discurso da violência e simultaneamente do exotismo e do erotismo, para além da ideia do nomadismo (cf. Magnus Berg, 2005 : 57, 60).

12. Nota de tradutor: De acordo com os conversores do Banco de Inglaterra, $£ 2$ em 1935 equivaleriam a cerca de $£ 143$ hoje em dia.

13. A edição Picador de The road to Oxiana não contém fotografias, mas o autor não só tinha o hábito de fotografar como o menciona no texto. Algumas estão acessíveis online.

14. Christopher Sykes, amigo de Byron, escreve que a viagem do autor foi « uma procura pelas origens da arte islâmica » (em Booth : 167).

15. William Dalrymple é um escritor de viagens, focado sobretudo na Índia. Um dos seus livros mais conhecidos é In Xanadu. A quest, que descreve uma longa viagem da Síria à China, feita pelo autor com duas raparigas, quando era mais novo. Ver Tim Youngs, 2005.

16. A Estrada para Oxiana, Lisboa, (2014), editada pela Tinta-da-China, com tradução de Raquel Mouta. Doravante será utilizada esta edição para todas as citações da obra de Byron. A obra será referida por RB, seguida doa referência à página.

17. Um exemplo oposto é o do relato de Ella Maillart, que viajou para o Afeganistão na companhia de Annemarie Schwarzenbach em 1939. No livro de Maillart (2000), Annemarie é representada pela figura de Christina, figura central da narrativa, para além da narradora, alter ego da autora.

18. Para esta contagem usei a edição inglesa da Picador. 
19. Veja-se este comentário crítico face à visão de alguns ingleses : «Houve um incidente diplomático quando a esposa do diplomata Harold Nicolson disse ao público inglês que não conseguia encontrar compota de laranja em Teerão » (RB :44).

20. Nota de tradutor : a tecnologia aqui referida é também mencionada na obra de Byron como gasogénio, um projecto para procurar alternativas aos combustíveis tradicionais.

21. Buruma e Margalit dizem que Reza Pahlavi atacou as tradições persas e as suas formas de vestir, inclusivamente as dos mullahs. Para estes autores, o movimento revolucionário islâmico nunca teria existido sem o secularismo rigoroso do regente persa nem sem as tentativas falhadas de instalar o socialismo no Egito, na Síria e na Algéria (Buruma, Margalit : 119 e 146).

22. Os sassânidas governaram a Pérsia de 224 a 644 ; trata-se do último império iraniano antes da conquista muçulmana da Pérsia.

23. Bernard Partridge (1861-1945) era um cartoonista conservador da revista Punch.

24. Byron escreve erradamente o nome do poeta com dois 's'.

\section{RÉSUMÉS}

Serão analisados dois relatos de viagem à Pérsia : um pela sueca Maud von Rosen, outro pelo britânico Robert Byron, efectuadas nos anos 30. Interessa-me sobretudo analisar o modo como o Outro é visto e a influência dos contextos europeus de origem no modo de encontrar o Outro, quer social quer geográfico. Os viajantes deparam-se com um dilema: apoiar as inovações civilizacionais do ocidente, para melhorar as condições de vida (vistas por ocidentais) e o consequente desaparecimento de muitas tradições. Ambos os viajantes são muito críticos face aos viajantes/turistas, pouco interessados na realidade persa, interessados sobretudo em confirmar os estereótipos de partida sobre o Médio Oriente.

The focus of this paper is on two travel books: one by the Swedish Maud von Rosen, the other by the British Robert Byron, during the thirties. I am specially interested to analyze how the Other is seen and the influence of European contexts where the travelers come from in the way they meet the Other, both socially and geographically. Most travelers in this time were before a dilemma: they appreciate the efforts of modernization imposed by the Western European countries and the effects it has on the traditions of the people. Both writers chosen are very critical towards the western travelers/tourists, who just want to confirm the ideas they had from home, and not open enough to see the differences.

\section{INDEX}

Palavras-chave : literatura de viagens, médio oriente, europa, Rosen (Maud von), Byron (Robert) Keywords : travel literature, middle East, europe, Rosen (Maud von), Byron (Robert) 
AUTEUR

GONÇALO VILAS-BOAS

ILCML/FLUP

gonvilasboas[at]gmail.com 